\title{
Optimizing use of basiliximab in liver transplantation
}

REVIEW

This article was published in the following Dove Press journal:

Transplant Research and Risk Management

30 December 2009

Number of times this article has been viewed

\section{Carlo B Ramirez \\ Adam Bozdin \\ Adam Frank \\ Warren Maley \\ Cataldo Doria}

Department of Surgery, Thomas Jefferson University, Philadelphia, PA, USA
Correspondence: Carlo B Ramirez Division of Transplantation, Department of Surgery, Thomas Jefferson University, 605 College Bldg., I025 Walnut St., Philadelphia, PA 19107, USA

Email carlo.ramirez@jefferson.edu
Abstract: Antibody induction therapy has not been part of standard immunosuppressive regimens in liver transplantation. However, in recent years there has been an upward trend in the use of antibody induction therapy in orthotopic liver transplantation (OLT), attributed mainly to the growing number of OLT recipients with renal dysfunction after the Model for End Stage Liver Disease (MELD) scoring system was adopted in 2002. Basiliximab, a chimeric monoclonal antibody, is the most frequently used induction antibody in OLT. Basiliximab targets the alpha chain of interleukin-2 receptors in activated T-lymphocytes, inhibiting T-lymphocyte proliferation responsible for acute cellular rejection. Basiliximab (given in two $20 \mathrm{mg}$ doses intravenously on post OLT day 0 and 4 ) has an excellent efficacy and safety profile. Basiliximab induction also allows early steroid withdrawal or avoidance, as well as delayed introduction and minimization of calcineurin inhibitors (CNI) in the setting of renal insufficiency. Although its long-term effect on hepatitis $\mathrm{C}$ virus (HCV) recurrence post OLT is currently unknown, studies using basiliximab induction in steroid-free protocols suggest no harmful effect on histologic HCV recurrence and survival rates. Basiliximab is a well tolerated, effective and safe anti-rejection drug in pediatric and adult OLT recipients when given in conjunction with a CNI-based immunotherapy.

Keywords: liver transplantation, basiliximab, acute cellular rejection, immunosuppression, steroids

\section{Introduction}

Orthotopic liver transplantation (OLT) is recognized as the standard therapy for end stage liver disease secondary to chronic and acute liver diseases. Currently, the adjusted 1 - and 5-year patient and graft survival rates after deceased-donor OLT are $87 \%$ and $73 \%$ and $83 \%$ and $68 \%$, respectively. ${ }^{1}$ Despite major advances in immunosuppression, acute cellular rejection (ACR) remains a significant postoperative problem. Although single episodes of acute rejection do not have a deleterious effect on graft function, ${ }^{2}$ long-term, recurrent episodes may result in permanent damage to the liver and may compromise long term graft survival. ${ }^{3}$

Induction therapy with antibodies is generally used in organ transplantation to decrease the incidence and delay the onset of acute rejection in the immediate posttransplant period, when the risk of rejection is the highest. In OLT, however, antibody induction therapy has not gained widespread use and typically has not been part of immunosuppressive regimens until recently. In fact, from 1997 to 2003, the number of transplant centers using antibody induction therapy in OLT has increased from $7 \%$ to $20 \% .{ }^{4}$ Basiliximab was the most frequently used (in $7 \%$ of OLT recipients) induction submit your manuscript | www.dovepress.com

Dovepress
Transplant Research and Risk Management 2010:2 1-10

(C) 2010 Ramirez et al, publisher and licensee Dove Medical Press Ltd. This is an Open Access article which permits unrestricted noncommercial use, provided the original work is properly cited. 
agent, followed by rabbit anti-thymocyte globulin (RATG) and daclizumab (both in $6 \%$ of OLT recipients). This trend may be attributed to the growing number of OLT recipients with renal insufficiency or end stage renal disease (ESRD) since the Model for End Stage Liver Disease (MELD) scoring system was adopted in 2002. Induction agents have been used to delay the introduction of calcineurin inhibitors (CNI), primarily to avoid CNI neurotoxicity or nephrotoxicity in the setting of renal insufficiency. Another potential setting in which induction therapy may prove useful in OLT is in early steroid withdrawal or steroid avoidance regimen, to minimize known steroid adverse effects, while maintaining adequate immunosuppression. Therefore, selecting an immunosuppressive regimen that not only minimizes the risk of severe acute allograft rejection but also decreases the risk of complications (ie, renal insufficiency) and other adverse drug effects is important to achieve long term graft survival after OLT and improve quality of life.

Two types of antibodies currently used in clinical transplantation for induction therapy are polyclonal and monoclonal antibodies. Polyclonal antibodies are gamma globulins produced by several clones of animal cells (horse or rabbit) immunized with human thymocytes or lymphocytes. Consequently, they have nonspecific immunosuppressive effects resulting mainly from massive lymphocyte depletion. The major adverse effects of polyclonal antibodies include serum sickness, anti-idiotype antibody formation, leucopenia and thrombocytopenia, cytokine release syndrome (due to mass release of cytokines after opsonization and destruction of mature T-cells), and significantly increased risk of infection and malignancy. ${ }^{5}$

On the other hand, monoclonal antibodies, such as the chimeric interleukin-2 receptor (IL-2R) antibody (basiliximab) and the humanized IL-2R antibody (daclizumab), selectively block the $\alpha$-chain (CD25) of IL-2 receptors (IL-2R), which are expressed only on activated T-lymphocytes, and prevent ACR by inhibiting IL-2 driven T-lymphocyte proliferation. Therefore, they offer a more specific immune response and less adverse effects than polyclonal antibodies. Several studies comparing IL2-R monoclonal antibody (basiliximab) and rabbit-derived polyclonal antibody (anti-thymocyte globulin, or ATG) in renal transplant recipients showed that basiliximab offered considerable advantages over ATG in terms of convenience of administration (two-dose regimen) and lower incidence of adverse effects (leucopenia, thrombocytopenia, and CMV infection), with no evidence of cytokine release syndrome. ${ }^{6-8}$

The immunologic process of ACR is mainly a result of T-cell activation and proliferation. The immune process begins with foreign antigens from the graft binding to antigen-presenting cells which subsequently activate T-cells. These cells then release IL-2 which binds to IL-2 receptors (IL-2R). This binding initiates an immune response characterized by cell proliferation and clonal expansion of activated T-cells as well as the generation of cytotoxic T-cells specific for graft antigens. ${ }^{9}$ Damage to the graft occurs when other $\mathrm{T}$ and B-cells are then activated causing occlusion of the graft vasculature and release of pro-inflammatory chemotactic chemicals that recruit even more lymphocytes as well as macrophages. ${ }^{10}$

\section{Methods}

This review article provides a synopsis of the efficacy and safety of basiliximab use in adult and pediatric OLT. The authors searched PubMed, Cochrane database, and Ovid Medline for studies published between 1950 and 2009, with the following search terms: basiliximab, Simulect, monoclonal, antibody, interleukin-2 antibody, and liver transplantation.

\section{Mechanism of action}

Basiliximab (Simulect ${ }^{\circledR}$; Novartis, Basel, Switzerland) was approved by the Food and Drug Administration (FDA) in May 1998 for prophylaxis against rejection in adult and pediatric kidney transplant patients in combination with dual (CNI and steroids) or triple (CNI, azathioprine, or mycophenolate mofetil, and steroids) maintenance immunosuppression.

Basiliximab is a chimeric ( $75 \%$ human and $25 \%$ murine) monoclonal antibody derived from an IL-2R $\alpha(\mathrm{CD} 25)$-specific parental murine monoclonal antibody, RFT5 $2 \mathrm{a}$. Using genetic engineering technology, the variable region genes of the murine antibody are fused to the constant region genes of the human antibody. IL-2R $\alpha$ (CD25) antibody specificity and affinity are maintained since the murine variable region remains unchanged. However, this chimeric antibody is less immunogenic in humans because the murine constant region is replaced with the human equivalent. The purified preparation is formulated as a lyophilizate and meets all quality control criteria for monoclonal antibodies intended for use in humans. ${ }^{11,12}$ basiliximab binds with similar affinity as IL- 2 to the $\alpha$-chain (CD25) of IL-2R on the surface of activated T lymphocytes. Consequently, the drug effectively competes with IL-2, and inhibits IL-2 driven T-lymphocyte proliferation, which is a critical phase of allograft rejection.

\section{Pharmacokinetic profile}

Several clinical studies in adult and pediatric OLT recipients have evaluated pharmacokinetic properties of basiliximab in 
conjunction with a number of maintenance immunosuppressive regimens. ${ }^{13-15}$ This drug has been shown to have biphasic and slow clearance with a long terminal half-life. This drug is characterized by a volume of distribution within the plasma compartment as well as outside the circulatory system, and is slowly broken down and eliminated from the body by intracellular proteolysis.

Basiliximab has a high volume of distribution $(\mathrm{Vd})$, consistent with plasma volume of distribution almost completely saturating IL-2R on peripheral T lymphocytes within 24 hours after a single dose of $2.5 \mathrm{mg}$ to $25 \mathrm{mg}$ as described in renal transplant recipients. ${ }^{8,13}$ In OLT, the $\mathrm{Vd}$ in the plasma compartment is reported as $5.7 \pm 0.9 \mathrm{~L}$ in adults and $2 \pm 0.9 \mathrm{~L}$ in children, while the steady state volume (Vs) is reported as $9.7 \pm 4.2 \mathrm{~L}$ in adults and $4.1 \pm 3.9 \mathrm{~L}$ in infants and children. ${ }^{13-15}$

Complete IL-2R $\alpha$ saturation is achieved when serum basiliximab concentration is reported to be $\geq 0.1 \mathrm{ug} / \mathrm{ml}$ (by ELISA) in liver transplant recipients. ${ }^{14}$ The duration of IL-2R $\alpha$ receptor saturation and suppression was $23 \pm 7$ days and $27 \pm 11$ days in adult and pediatric OLT recipients, respectively. ${ }^{13,15}$ It was observed that the incidence and onset of ACR was independent of basiliximab clearance and duration of IL-2R $\alpha$ saturation. There was no difference in the duration of IL-2R $\alpha$ saturation between recipients who developed ACR compared to those who did not. ${ }^{15,16}$

Total body clearance was significantly faster for OLT recipients compared to renal transplant recipients $(75 \pm 24$ vs $46 \pm 16 \mathrm{ml} / \mathrm{h}, P=0.0001)$ while the terminal elimination half life was shorter $(4.1 \pm 2.1$ vs $5.8 \pm 2$ days, $P=0.007) .{ }^{15}$ Since it is expected that a large antibody like basiliximab cannot filter through the kidneys unless there is significant proteinuria, these differences in clearance were attributed to non-renal routes, such as ascitic drainage and post-operative blood loss. ${ }^{14}$ Although ascitic drainage accounted for only $20 \%$ of total basiliximab clearance, in the presence of massive ascitic drainage, basiliximab clearance may be clinically significant, warranting individualized drug dosing in specific cases. On the other hand, increased blood loss seen in OLT has little contribution to basiliximab clearance; therefore there is no evidence to support basiliximab dose adjustments based on volume of postoperative bleeding. 13,14

The suggested basiliximab dosing is generally the same in OLT as in kidney transplantation. However, the first dose is given within 4 hours after liver graft reperfusion, to avoid drug losses from blood loss and massive ascites. The second dose is given on the fourth day after transplantation as in kidney transplant recipients. An additional basiliximab dose of 10 to $20 \mathrm{mg}$ depending on the recipient body weight may be recommended on postoperative day 7 for ascitic drainage $>5$ to $10 \mathrm{~L}$ within the first week post OLT. ${ }^{13}$

In adult OLT recipients, the recommended dose of basiliximab is two $20 \mathrm{mg}$ doses infused via a central or peripheral intravenous line over 20 to 30 minutes. In infants and children less than 9 years of age $(n=30)$, basiliximab clearance was reduced by $50 \%$ compared with adult OLT recipients. This finding was independent of age up to 9 years old, weight up to $30 \mathrm{~kg}$, and body surface area to $1 \mathrm{~m}^{2}$. Clearance in children 9 to 14 years of age and adolescents was similar to that of adults. Therefore, the recommended basiliximab dose for pediatric recipients $\leq 35 \mathrm{~kg}$ is $10 \mathrm{mg}$, and $20 \mathrm{mg}$ for recipients $\geq 35 \mathrm{~kg}$, given in 2 doses with the first given on day of transplant and second on the fourth post-transplant day. ${ }^{15,16}$ Routine monitoring of serum levels is not currently recommended for basiliximab. The pharmacokinetic characteristics of basiliximab are summarized in Table 1.

\section{Efficacy studies}

Results of large, multi-center, placebo-controlled, randomized clinical trials, which were conducted mainly in renal transplant recipients, have demonstrated the efficacy and safety of basiliximab induction in preventing rejection. ${ }^{12,17-19}$ In these trials, the incidence of ACR was significantly reduced by $12 \%$ to $14 \%$ in the basiliximab induction group compared to placebo. Furthermore, the incidence of corticosteroid-resistant ACR (requiring antibody therapy) at 6 and 12 months was significantly lower in the basiliximab compared to placebo group $(10 \%$ vs $23.1 \%, P<0.001)$ in the European/Canadian trial. ${ }^{12}$ Similarly, significantly fewer recipients in the basiliximab than in the placebo group (25\% vs $42 \%, P=0.001$ ) experienced steroid-resistant ACR that required antibody therapy and/or azathioprine, Tac, or MMF. ${ }^{17}$ However, despite reduction of early ACR episodes,

Table I Pharmacokinetic profile of basiliximab

\begin{tabular}{lll}
\hline $\begin{array}{l}\text { Pharmacokinetic } \\
\text { characteristic }\end{array}$ & Adult $>\mathbf{3 5} \mathbf{~ k g}$ & Pediatric $<\mathbf{3 5} \mathbf{~ k g}$ \\
\hline $\begin{array}{l}\text { Dose } \\
\text { Ist dose: OLT day 0 (mg) }\end{array}$ & 20 & 10 \\
2nd dose: OLT day 4 (mg) & 20 & 10 \\
Volume of distribution (L) & $5.7 \pm 0.9$ & $2 \pm 0.9$ \\
Steady state volume (L) & $9.7 \pm 4.2$ & $4.1 \pm 3.9$ \\
Elimination half life (days) & $8.7 \pm 6.7$ & $7.6 \pm 4.6$ \\
Total body clearance (mL/h) & $55 \pm 26$ & $19.3 \pm 6.5$ \\
Duration of IL-2R $\alpha$ & $23 \pm 7$ & $27 \pm 11$ \\
saturation (days) & & \\
\hline
\end{tabular}

Abbreviation: OLT, orthotopic liver transplantation. 
the 12-month graft and patient survival rates were similar in the two treatment groups.

Experience with the use of basiliximab induction in liver transplantation is less extensive.

\section{Adult OLT recipients}

A large, multi-center, double-blind, randomized trial involving 381 OLT recipients, stratified by hepatitis C (HCV) seropositivity, compared basiliximab to placebo in conjunction with cyclosporine (CsA) and steroid maintenance therapy. ${ }^{20}$ In this study, the incidence of ACR episodes at 6 months post OLT was significantly lower in the basiliximab (35\% vs 44\%) compared to the placebo group. The reduction in ACR rate was more pronounced in the HCV-negative cohort, with much smaller difference seen in the HCV-positive cohort. Furthermore, the incidence of corticosteroid-resistant ACR was lower in the basiliximab compared to the placebo group at 6 months post OLT $(18 \%$ vs $25 \%, P=0.09)$ and at 12 months post OLT $(18 \%$ and $26 \%, P=0.05)$. The 1 -year graft and patient survival rates in the basiliximab group were similar to those of the placebo group ( $84 \%$ vs $80 \%$ and $87 \%$ vs $84 \%$, respectively).

In a multi-center, single-arm, open-label study, Calmus et $\mathrm{al}^{21}$ investigated the efficacy and tolerability of basiliximab induction with CsA, Azathioprine (AZA) and steroid maintenance immunosuppression in their first 101 OLT recipients. The authors reported an ACR rate of $23 \%$ at 6 months, none of which was labeled histologically as severe and required antibody therapy. Furthermore, there was no difference in grade of rejection between the HCV-positive and HCVnegative groups. The 1-year graft and patient survival rates were $88 \%$ and $90 \%$, respectively.

A prospective, randomized, single-center study conducted in 47 adult OLT recipients compared basiliximab and CsA to steroids and CsA. ${ }^{22}$ They demonstrated a lower ACR rate (15\% vs 29\%, respectively) and a higher cumulative survival at 36 months post OLT (84\% vs 61\%, respectively) in the basiliximab and CsA group compared to the steroid and CsA group.

Several single-center experiences with the use of basiliximab induction in conjunction with dual (CNI and steroids) or triple (CNI, mycophenolate mofetil, or MMF, and steroids) maintenance immunotherapy in adult deceased-donor and living-donor OLT recipients, reported lower ACR rates of 7\% to $27 \%$ and similar 1-year graft and patient survival rates of $88 \%$ to $93 \%$ and $90 \%$ to $94 \%$, respectively. ${ }^{23-26}$ In a singlecenter, retrospective analysis of 42 consecutive deceaseddonor, adult OLT recipients who received basiliximab induction with maintenance tacrolimus (Tac), MMF and early steroid taper, Ramirez et $\mathrm{al}^{25}$ reported a $93 \%$ rejection-free patient and graft survival rate after a 2-year follow-up.

\section{Pediatric OLT recipients}

In the pediatric OLT population, several single-center trials using basiliximab induction have consistently shown significant reduction in ACR episodes. ${ }^{27-33}$ Several studies comparing a steroid-free immunosuppressive regimen with basiliximab induction to a steroid-containing regimen showed a significantly higher growth catch up post OLT in the basiliximab group. ${ }^{27,29}$

In a prospective randomized trial, Reding et $\mathrm{al}^{27}$ compared 20 pediatric OLT recipients who received basiliximab induction and Tac, to 20 matched historical control group patients who received steroid induction and Tac. At 1 year post OLT, they observed a significantly higher growth catch up starting in the first week post OLT in the basiliximab group, and growth delay in the steroid group until the introduction of alternate day steroid treatment. They also noted a significantly higher rejection-free 1 -year survival in the basiliximab group as compared to the steroid group (75\% vs 50\%, respectively).

Spada et $\mathrm{al}^{28}$ conducted a prospective randomized study on 72 pediatric OLT with recipients equally distributed between those treated with basiliximab and Tac to those treated with steroids and Tac. The basiliximab group had a statistically significant lower incidence of rejection and infection. Although not statistically significant, the 1-year patient (91\% vs $89 \%$ ) and graft (86\% vs $80 \%$ ) survival rates favored the steroid arm.

In another prospective study, Gras et $\mathrm{al}^{29}$ treated 50 pediatric OLT recipients with a steroid-free, Tac-based immunosuppression and compared the outcome to a historical control group of 34 pediatric OLT recipients treated with Tac and steroids. They reported a 3-year rejection-free graft survival rate of $72 \%$ and $41 \%(P=0.007)$ in the basiliximab and steroid groups, respectively. The incidence of viral infections was significantly less in the basiliximab group compared to the steroid group. Furthermore, there was growth catch up in the basiliximab group starting at 3 months post OLT. At 3 years post OLT, their height has reached the average of nontransplant children of the same age and gender. In contrast, patients in the steroid group had only significant growth improvement at 2 years and 3 years post-OLT. At 3 years post OLT, the mean height of recipients in this group was below the average of non-transplant children of the same age and gender.

Ganschow et $\mathrm{al}^{30}$ compared the outcomes of 54 pediatric OLT recipients (transplanted in 1999 to 2000) who received basiliximab, CsA and steroids to a historical group of 
54 pediatric OLT recipients (transplanted in 1997 to 98) who received CsA and steroids only. They reported a significant reduction of ACR rate in the basiliximab group compared to the historical group ( $16 \%$ vs $54 \%$, respectively), after a follow-up period of 22 to 46 months. The incidence of steroid resistant rejection, chronic rejection, infection, PTLD, and patient survival were not statistically different.

Table 2 summarizes selected published efficacy studies on basiliximab use in adult and pediatric OLT.

\section{Safety profile}

The safety profile of basiliximab was studied extensively in several randomized trials conducted mainly in renal transplant patients. Data from the US and European/Canadian multicenter prospective randomized trials have all reported no significant difference in the type, incidence, and severity of adverse events in patients who received basiliximab compared with placebo. ${ }^{12,17-19}$ Similar findings were reported in studies conducted on OLT recipients. ${ }^{20-22}$ In both clinical studies comparing basiliximab to placebo 20 and basiliximab to corticosteroids, ${ }^{22}$ there was no reported difference in the incidence of infection and other adverse events between treatment groups.

Basiliximab is better tolerated and safer to use than Muromonab OKT3. Basiliximab has not been shown to cause cytokine release syndrome which consists of fever, chills, headache, and pulmonary edema. This syndrome is commonly observed with Muromonab OKT3 administration and was seen in comparative studies of the two agents. ${ }^{12,19}$

Despite the 305 murine variable region sequences in basiliximab, it is surprisingly minimally immunogenic demonstrating an anti-idiotype sensitization of only $0.4 \%$ to $1.4 \% .{ }^{12,19}$ Even with the detection of these anti-idiotype antibodies, there was no association with increased risk of ACR or adverse events. ${ }^{34}$

Hypersensitivity reactions due to anti-idiotypic $\operatorname{IgE}$ antibody formation occurs rarely. ${ }^{35}$ In a postmarketing surveillance conducted in October 2000, a total of 17 cases of hypersensitivity reactions, including anaphylaxis, occurred after exposure or re-exposure to basiliximab. Further cases of anaphylactic shock reactions occurred mainly in pediatric recipients who were re-exposed to basiliximab after re-transplantation. ${ }^{35,36}$

The incidence of infections was similar in renal transplant recipients who received basiliximab compared to placebo in the US (73\% vs $75 \%$ ) and European trials ( $85 \%$ vs $86 \%) .{ }^{12,17}$ The incidence of cytomegalovirus infections in renal transplant recipients was likewise similar in the basiliximab and placebo groups in the European/Canadian (21\% vs $27 \%$ ) and the US (7\% vs 9\%) studies. Furthermore, the overall incidence of malignancy, and post-transplant lympho-proliferative disease (PTLD) in the first post-transplant year was similar $(0.3 \%$ and $0.6 \%$ ) in the basiliximab and placebo groups, respectively. In the combined European/Canadian trials, 2 neoplasms (both breast cancer) developed in the basiliximab group, and 6 neoplasms ( 3 basal cell carcinomas, one squamous cell carcinoma, one hypernephroma, and one lymphoma) developed in the placebo group. 12 In the US trials, 5 neoplasms were recorded during the 12-month follow up period, 3 in the basiliximab group ( 1 melanoma, 1 adenocarcinoma, and 1 cerebral glioma) and 2 (1 multiple myeloma and 1 Kaposi's sarcoma) in the placebo group. ${ }^{17}$

Basiliximab has been reported to cause a number of adverse effects including pain, hypertension, nausea, anemia, peripheral edema, headache, as well as hyperkalemia, yet there has not been any reported drug interaction with this induction agent. ${ }^{12}$ Due to the lack of animal reproduction studies with basiliximab there are no good data on its effect on fertility or the fetus itself. Due to the absence of adequate studies in pregnant women, the FDA has assigned basiliximab to category B. It is currently accepted that basiliximab should be avoided in pregnancy at this time because we know that IgG crosses the placenta, theoretically putting the fetus at risk.

\section{Specific uses of basiliximab in liver transplantation}

Induction therapy may have benefits in OLT recipients by allowing steroid avoidance/minimization and by allowing CNI minimization in the setting of renal dysfunction.

Steroids have always been part of standard post-transplant immunosuppression either for prophylaxis or treatment of ACR. However, susceptibility to infection, obesity, hypertension, hyperlipidemia, diabetes, osteopenia, cataracts, and growth retardation in children, are all well recognized longterm adverse effects of steroids. Steroids are also implicated in accelerating HCV recurrence post-OLT. ${ }^{37,38}$ Currently, $\mathrm{HCV}$ is the most common indication for liver transplantation, accounting for about $40 \%$ of all liver transplant cases. ${ }^{39}$ Due to long-term steroid adverse effects, strategies to minimize steroid exposure ranging from early steroid reduction and withdrawal to complete steroid avoidance post OLT have been adopted. In recent years, several prospective clinical trials using basiliximab induction to facilitate early steroid withdrawal ${ }^{40,41}$ or complete steroid avoidance have been successfully conducted in adult ${ }^{22,42-45}$ and pediatric ${ }^{27-29}$ OLT recipients.

Although the long term impact of basiliximab on HCVassociated recurrence is currently unknown, complete steroid avoidance protocols utilizing basiliximab induction suggest 
Table 2 Selected published efficacy studies on basiliximab use in adult and pediatric OLT

\begin{tabular}{|c|c|c|c|c|c|c|c|}
\hline Reference & Study type & No. of pts. & OLT type & Treatment groups & ACR rate & $\begin{array}{l}\text { Graft survival } \\
\text { (I year) }\end{array}$ & $\begin{array}{l}\text { Patient survival } \\
\text { (I year) }\end{array}$ \\
\hline \multicolumn{8}{|l|}{ OLT - adult } \\
\hline \multirow[t]{2}{*}{ Neuhaus et $\mathrm{a}^{20}$} & $M C, P R$ & 188 & DD & CsA, Ste, Bas & 35 & 84 & 87 \\
\hline & & 193 & & CsA, Ste, pl & 44 & 80 & 84 \\
\hline Calmus et $\mathrm{al}^{21}$ & MC,PR & 101 & $\mathrm{DD}$ & CsA, AZA, Ste, Bas & 23 & 88 & 90 \\
\hline \multirow[t]{2}{*}{ Lupo L et a ${ }^{22}$} & PR & 26 & $\mathrm{DD}$ & CsA, Bas & 15 & & \\
\hline & & 21 & & CsA, Ste & 29 & & \\
\hline Grannas et $\mathrm{al}^{23}$ & $\mathrm{R}$ & 102 & DD & CsA, Ste, Bas & 27 & 93 & 94 \\
\hline Marino et $\mathrm{a}^{24}$ & PR & 50 & $\mathrm{DD}$ & Tac, Ste, Bas & 12 & $75(3 y)$ & $88(3 y)$ \\
\hline Ramirez et $\mathrm{al}^{25}$ & $\mathrm{R}$ & 42 & DD & Tac, MMF, Ste, Bas & 7 & $93(2 y)$ & $93(2 y)$ \\
\hline Gruttadauria et $\mathrm{al}^{26}$ & $\mathrm{R}$ & 60 & LD & Tac, Ste, Bas & 5 & $76(3 y)$ & $82(3 y)$ \\
\hline \multirow[t]{2}{*}{ Filipponi et $\mathrm{al}^{44}$} & $M C, P R$ & 70 & DD & CsA, AZA, Bas, Ste & 24 & 73 & 85 \\
\hline & & 70 & & CsA, AzAa, Bas, pl & 39 & 82 & 89 \\
\hline \multicolumn{8}{|l|}{ OLT - pediatric } \\
\hline \multirow[t]{2}{*}{ Reding et $\mathrm{al}^{27}$} & $P R$ & 20 & DD & Tac, Bas & 94 & 75 & 75 \\
\hline & & 20 & & Tac, Ste (historical) & 74 & 50 & 50 \\
\hline \multirow[t]{2}{*}{ Spada et $\mathrm{a}^{28}$} & PR & 36 & DD & Tac, Bas & 11 & 80 & 89 \\
\hline & & 36 & & Tac, Ste & 31 & 86 & 91 \\
\hline \multirow[t]{2}{*}{ Gras et $\mathrm{al}^{29}$} & PR & 50 & DD & Tac, Bas & 28 & $94(3$ y) & $96(3 y)$ \\
\hline & & 34 & & Tac, Ste (historical) & 59 & $88(3 y)$ & $91(3 y)$ \\
\hline \multirow[t]{2}{*}{ Ganschow et $\mathrm{al}^{30}$} & & 54 & DD, LD & CsA, Ste, Bas & 17 & 98 & 98 \\
\hline & & 54 & & CsA, Ste (historical) & 54 & 94 & 94 \\
\hline \multirow[t]{2}{*}{ Asensio et $\mathrm{a}^{|3|}$} & $\mathrm{R}$ & 13 & DD & Tac, Ste, Bas & 30 & 80 & 80 \\
\hline & & 21 & & Tac, Ste & 63 & 80 & 80 \\
\hline Kovarik et al ${ }^{14}$ & $\mathrm{R}$ & 37 & DD & CsA, Ste, Bas & 55 & & \\
\hline \multirow[t]{4}{*}{ Strassburg et a $\mathrm{a}^{32}$} & $\mathrm{R}$ & 12 & & CsA, Ste & 42 & & 100 \\
\hline & & 9 & & CsA, AZA, Ste & 66 & & 100 \\
\hline & & 21 & & CsA, Ste, Bas & 33 & & 100 \\
\hline & & 12 & & Tac, Ste & 42 & & 100 \\
\hline \multirow[t]{2}{*}{ Gibelli et $\mathrm{a}^{33}$} & $\mathrm{R}$ & 32 & DD, LD & Bas, CsA, Ste & 57.1 & & \\
\hline & & 28 & & CsA, Ste (historical) & 67.8 & & \\
\hline
\end{tabular}

Abbreviations: MC, multicenter; R, retrospective; PR, prospective; DD, deceased donor; OLT, orthotopic liver transplantation; LD, living donor; Bas, basiliximab; Tac, tacrolimus; CsA, cyclosporine; AZA, azathioprine; MMF, mycophenolate mofetil; Ste, steroids; pl, placebo.

no significant difference in the incidence of histologic $\mathrm{HCV}$ recurrence and overall survival rates. ${ }^{42-45}$

Llado et $\mathrm{al}^{42}$ looked at the use of CsA with basiliximab in an open-label prospective randomized trial to evaluate the efficacy of a steroid free regimen, specifically in HCV recipients. They found that there was no significant difference in ACR observing a $17 \%$ and $21 \%$ rejection rate in the nonsteroid and steroid groups, respectively. Patient survival was also not significantly different between the two groups. They did, however, find significantly less bacterial infection in the steroid-free group ( $38 \%$ vs $59 \%$ ). They also saw $97 \%$ biopsy-proven HCV recurrence in both treatment groups.
Further evaluation was done by Lupo et $\mathrm{al}^{22}$ who conducted a prospective randomized control trial using CsA in both groups with two doses of $20 \mathrm{mg}$ of basiliximab in one group and $200 \mathrm{mg}$ hydrocortisone each day in the other group. They found similar findings as above demonstrating no significant differences in ACR, graft and patient survival, rejection-free survival, as well as infection rates.

In a 2-year, prospective, randomized trial, Ramirez et $\mathrm{al}^{43}$ compared steroid-free to standard steroid therapy in 39 OLT patients treated with basiliximab, Tac, and entericcoated mycophenolate sodium (EC-MPS). There were no significant differences between the steroid and steroid-free 
group in regard to hypertension, cholesterol levels, infection rates, or $\mathrm{HCV}$ recurrence from baseline to 1 year, although there was a trend toward lower weight gain in the steroidfree group. There was no CMV and malignancy observed in either group. Furthermore, the ACR rate (5\% in each group), as well as patient and graft survival rates were similar in the steroid and steroid-free group (100\% vs $95 \%$, respectively). The authors concluded that complete steroid avoidance with basiliximab, CNI, and EC-MPS, is as safe and effective as standard steroid therapy in adult OLT recipients.

Filipponi et $\mathrm{al}^{44}$ examined a steroid-free regimen in $140 \mathrm{HCV}$-infected transplant recipients in a double-blinded, randomized clinical trial. Both groups received 2 doses of $20 \mathrm{mg}$ of basiliximab, CsA, and azathioprine with appropriate dose adjustments. One group then received a tapering regimen of methylprednisolone and oral prednisone while the other group received placebo. They found no significant differences in 12 -month HCV histologic recurrence (41.2\% vs $37.5 \%$ in steroid and placebo groups, respectively). However, a lower treatment failure rate (defined as death, graft loss, or study discontinuation for adverse events) was observed in the steroidfree group as compared to the placebo group (16\% vs $28 \%$, respectively). They did also find that biopsy-proven ACR was lower in the steroid group ( $24.3 \%$ vs $39.4 \% ; P=0.04$ ); however, there was no significant difference in treated ACR.

Segev et $\mathrm{al}^{46}$ conducted a meta-analysis of randomized control trials looking at steroid avoidance in adult post-OLT patients, including 4 trials using basiliximab induction. It was shown that there were no significant differences in graft loss, death, and infection. They did, however, find a significant decrease in serum cholesterol levels and CMV infection. The relative risk (RR) for CMV in steroid-free groups was 0.52 $(P=0.001)$. In studies where they replaced steroids with an alternate immunosuppressive agent, they found a RR of 0.29 for new-onset diabetes in the steroid-free groups $(P<0.001)$, decreased rejection rates with a $\mathrm{RR}$ of $0.68(P=0.03)$, as well as decreased severe rejection with a $\mathrm{RR}$ of $0.37(P=0.001)$. In those studies where steroids were just removed from a regimen without replacement, rejection was found to be higher in the steroid-free arm, the RR being $1.31(P=0.02)$. Despite no significant reduction in $\mathrm{HCV}$ recurrence within any individual trial, this meta-analysis demonstrated a RR of $0.90(P=0.03)$ in HCV recurrence in the steroid-free groups. Given the data shown above, it has been demonstrated that steroid-free immunosuppressive regimens in OLT recipients can be safe and efficacious, and basiliximab appears to be an effective substitute in the induction phase of postoperative therapy.
Currently, renal insufficiency and ESRD after OLT represent extremely serious challenges facing OLT recipients, complicating patient management, and increasing risk of morbidity and mortality. OLT recipients have the highest incidence of ESRD of all nonrenal organ transplant recipients apart from intestinal transplants affecting more than $20 \%$ of OLT recipients. ${ }^{47,48}$ Furthermore, recipients who develop ESRD after OLT have a 4-fold higher risk of death and significantly lower survival rates compared to those without ESRD ( $28 \%$ vs 55\%). ${ }^{47,48}$ The most common cause of ESRD after OLT is CNI-induced nephrotoxicity $(75 \%)$ followed by progression of underlying renal disease (11\%), hepato-renal syndrome $(7 \%)$, and focal sclerosing glomerulosclerosis (7\%). ${ }^{49}$

The impact of CNIs on renal function and the fact that early kidney dysfunction is a predictor of late chronic renal failure after OLT, ${ }^{50}$ have led to a number of studies exploring the use of antibody induction to delay or minimize CNI exposure $^{51-56}$ In a prospective, open-label, nonrandomized study using basiliximab induction followed by delayed initiation (median delay 36 hours) and reduced dose (trough level of 5 to $10 \mathrm{ng} / \mathrm{mL}$ ) of Tac with maintenance MMF and steroid taper, Lin et $\mathrm{al}^{54}$ demonstrated a "renal-sparing" effect of basiliximab induction in adult living donor OLT. They reported a significantly lower incidence of renal insufficiency at the third post-OLT month in the basiliximab group compared to the control (no induction) group (26\% vs $67 \%$ ) with similar incidence of ACR, CMV infection, and new-onset diabetes mellitus. Another clinical trial in 25 OLT recipients using basiliximab induction with low-dose Tac (trough levels 4 to $5 \mathrm{ng} / \mathrm{mL}$ ), reported recovery of renal function in more than $80 \%$ of recipients without increasing the incidence of infections or adverse effects, and an ACR rate of $28 \% .{ }^{56}$

More than $90 \%$ of OLT recipients who develop ACR respond to standard steroid regimen consisting of methylprednisolone intravenous bolus followed by tapering doses of the drug. The conventional treatment for steroid resistant ACR includes the use of T-cell antibodies, such as anti-thymocyte globulin and murine monoclonal antibodies (OKT-3). However, these drugs are associated with potentially significant side effects, such as cytokine release syndrome, and increased risk of infection and malignancy, particularly PTLD in children. ${ }^{57}$ Another rescue treatment protocol that has been tried successfully was high-dose Tac, ${ }^{58}$ although its nephrotoxic adverse effect has been a major limiting factor to its use.

Several studies have shown the potential of basiliximab as a safe and effective alternative to OKT-3 and high-dose 
Tac for rescue therapy in steroid resistant rejection. ${ }^{59-61}$ In a study on 7 pediatric OLT recipients with biopsy-proven steroid resistant ACR who were given basiliximab in 2 doses 3 to 7 days apart, only 2 recipients did not respond to rescue therapy and progressed to chronic rejection, while 5 recipients were treated successfully and were rejection free at a median follow up of 22 months (range: 5 to 32 months). ${ }^{59}$ Another study described their experience with the use of anti-IL2-R antibodies (daclizumab or basiliximab) as rescue therapy for steroid-resistant rejection in 25 adult OLT recipients. In this study, the median time from OLT to onset of steroid-resistant rejection was 25 days. Twelve patients (48\%) had complete resolution of rejection, with aspartate transaminase levels normalizing at a median of 37 days (range: 1 to 168 days). A total of 13 patients (52\%) developed progressive liver dysfunction leading to death with graft failure $(n=3)$, retransplantation $(n=4)$ and chronic rejection $(n=6)$. Looking at the liver graft biopsy findings, all patients who were treated successfully had ACR, while those who responded poorly already had chronic rejection histologically. ${ }^{60}$

\section{Pharmacoeconomic evaluation}

The use of the standard two $20 \mathrm{mg}$ doses of basiliximab induction to the immunosuppressive regimen would entail an additional US\$3,000 to the total medical cost after transplantation. However, pharmacoeconomic studies conducted in kidney transplant recipients showed that basiliximab use is cost-effective compared to placebo, and this is attributed to reduction in the incidence of ACR, graft loss or delayed graft function, and consequent shorter hospital stay, decreased need for dialysis, and reduced hospital admission to treat ACR. ${ }^{62-64}$ The US multicenter trial comparing basiliximab, CsA and steroids vs placebo, $\mathrm{CsS}$ and steroids in 346 kidney transplant recipients demonstrated a significant reduction in ACR rate (38\% vs 55\%) and fewer hospital admissions to treat ACR in the basiliximab vs placebo group, respectively. ${ }^{17}$ The cost analysis showed lower total first-year medical costs (US\$28,927 vs US\$32,300, difference of US\$3,373), and lower first-year hospital costs (US\$9,328 vs US\$10,761, difference of US\$1,433) for treating ACR in the basiliximab compared to the placebo group, although the differences were not statistically significant. ${ }^{62}$ The pharmacoeconomic evaluation of 380 adult kidney transplant recipients in the European/ Canadian multi-center trial. ${ }^{12}$ demonstrated that basiliximab use generated a net cost savings of CAN\$1,554 (including drug cost) per patient in the first post-transplant year. ${ }^{63}$

\section{Conclusion}

Induction with basiliximab, an anti-IL2-R monoclonal antibody, in combination with a CNI-based immunosuppressive therapy, is an effective and safe strategy for immunoprophylaxis in pediatric and adult OLT recipients. The high selectivity of this monoclonal antibody makes this drug an effective immunoprophylaxis in liver transplantation without increasing the risk of infection, HCV recurrence, malignancy, or other adverse effects. Basiliximab induction appears to be a safe substitute to steroids in early steroid withdrawal or complete steroid avoidance protocols. In the setting of renal insufficiency, basiliximab induction also allows for delayed introduction of CNIs to avoid CNI nephrotoxicity and preserve renal function without increasing the risk of rejection or compromising patient and graft survival in OLT recipients. Pharmacoeconomic analyses have also furnished evidence of the cost-effectiveness of basiliximab induction therapy. The combination of minimal dosing requirements without serum level monitoring, and proven therapeutic efficacy and excellent safety profile, makes this drug an ideal choice for induction therapy in OLT.

\section{Disclosures}

The authors disclose no conflicts of interest.

\section{References}

1. OPTN/SRTR 2008 Annual Report. URL: http://ustransplant.org/ annualreport. Accessed May 1, 2008.

2. Seiler CA, Renner EL, Czerniak A, et al. Early acute cellular rejection: no effect on late hepatic allograft function in man. Transpl Int. 1999;12: 195-201.

3. Dousset B, Conti F, Cherruau B, et al. Is acute rejection deleterious to long term liver allograft function? J Hepatol. 1998;29:660-668.

4. Shapiro R, Young JB, Milford EL, et al. Immunosuppression: Evolution in practice and trends, 1993-2003. Am J Transplant. 2005;5:874-886.

5. Brennan DC. Action, efficacy and toxicities: polyclonal anti-lymphocyte antibodies. In: Norman DJ, Turka LA, editors. Primer on Transplantation. 2nd ed. Mt. Laurel (NJ): American Society of Transplantation; 2001. P. 152.

6. Sollinger H, Kaplan B, Peskovitz MD, et al. Basiliximab vs antithymocyte globulin for prevention of acute renal allograft rejection. Transplantation. 2001;72:1915-1919.

7. Lebranchu Y, Bridoux F, Buchler M, et al. Basiliximab vs antithymocyte globulin in renal transplantation. Am J Transplant. 2002;2:48-56.

8. Mourad G, Rostaing L, Legendre C, et al. Sequential protocols using Basiliximab vs anti-thymocyte globulins in renal-transplant patients receiving mycophenolate mofetil and steroids. Transplantation. 2004;78:584-590.

9. Rob RJ, Greene WC, Rusk CM. Low and high affinity cellular receptors for interleukin 2: implications for the level of Tac antigen. J Exp Med. 1984;160:1126-1146.

10. Feldmann F. Cell cooperation in the antibody response. In: Roitt I, Bronstoff J, Male D, editors. Immunology. 4th ed. London: Times Mirror International Publishers; 1996. p. 8.1-8.16.

11. Amlot PL, Rawlings E, Fernando ON, et al. Prolonged action of a chimeric interleukin-2 receptor (CD25) monoclonal antibody used in cadaveric renal transplantation. Transplantation. 1995;60:748-756. 
12. Nashan B, Moore R, Amlot P, et al. Randomized trial of basiliximab vs placebo for control of acute cellular rejection in renal allograft recipients. Lancet. 1997;350:1193-1198.

13. Kovarik JM, Nashan B, Neuhaus P, et al. A population pharmacokinetic screen to identify demographic-clinical covariates of basiliximab in liver transplantation. Clin Pharmacol Ther. 2001;69:201-209.

14. Kovarik JM, Breidenbach T, Gerbeau C, et al. Disposition and immunodynamics of basiliximab in liver allograft recipients. Clin Pharmacology Ther. 1998;64:66-72.

15. Kovarik JM, Gridelli BG, Martin S, et al. Basiliximab in pediatric liver transplantation: a pharmaco-kinetic derived dosing algorithm. Pediatr Transplant. 2002;6:224-230.

16. Kovarik JM, Offner G, Broyer M, et al. A rational dosing algorithm for basiliximab (Simulect) in pediatric renal transplantation based on pharmacokinetic-dynamic evaluations. Transplantation. 2002;74:966-971.

17. Kahan BD, Rajagopalan PR, Hall M. Reduction of the occurrence of acute cellular rejection among renal allograft recipients treated with basiliximab, a chimeric anti-interleukin-2- receptor monoclonal antibody. Transplantation. 1999;67:276-284.

18. Ponticelli C, Yussim A, Cambi V, et al. A randomized double-blind trial of basiliximab immunoprophylaxis plus triple therapy in kidney transplant recipients. Transplantation. 2001;72:1261-1267.

19. Lawen JG, Davies EA, Mourad G, et al. Randomized double-blind study of immunoprophylaxis with basiliximab, an anti-interleukin-2 receptor monoclonal antibody, in combination with mycophenolate mofetilcontaining triple therapy in renal transplantation. Transplantation. 2003;75:37-43.

20. Neuhaus P, Clavien PA, Kittur D, et al. Improved treatment response with basiliximab immunoprophylaxis after liver transplantation: results from a double blind randomized placebo controlled trial. Liver Transpl. 2002;8:132-142.

21. Calmus Y, Scheele JR, Gonzalez-Pinto I, et al. Immunoprophylaxis with basiliximab, a chimeric interleukin-2 receptor monoclonal antibody, in combination with azathioprine-containing triple therapy in liver transplant recipients. Liver Transpl. 2002;8:123-131.

22. Lupo L, Piercarmine P, Tandoi F, et al. Basiliximab vs steroids in double therapy immunosuppression in liver transplantation: a prospective randomized clinical trial. Transplantation. 2008;86:925-931.

23. Grannas G, Lueck Rainer, Becker T, et al. Immunoprophylaxis with Simulect (basiliximab) in combination with cyclosporine and steroids in liver transplantation. Proceedings of the Transplant 2001 Meeting; 2001 May 11-16; Chicago, IL.

24. Marino IR, Doria C, Scott V, et al. Efficacy and safety of basiliximab with a tacrolimus based regimen in liver transplant recipients. Transplantation. 2004;78:886-891.

25. Ramirez C, Doria C, DiFrancesco F, et al. Anti-IL2 induction in liver transplantation with $93 \%$ rejection free patient and graft survival at 18 months. J Surg Res. 2007;138:198-204.

26. Gruttadauria S, Mandala L, Biondo D, et al. Role of basiliximab in the prevention of acute cellular rejection in adult to adult living-related liver transplantation: a single center experience. Biologics. 2007;1:69-73.

27. Reding R, Gras J, Sokal E, et al. Steroid free liver transplantation in children. Lancet. 2003;362:2068-2070.

28. Spada M, Petz W, Bertani A, et al. Randomized trial of Basiliximab induction vs steroid therapy in pediatric liver allograft recipients under tacrolimus immunosuppression. Am J Transplant. 2006;6: 1913-1921.

29. Gras JM, Gerkens S, Beguin C, et al. Steroid-free, tacrolimus-basiliximab immunosuppression in pediatric liver transplantation: clinical and pharmaco-economic study in 50 children. Liver Transpl. 2008;14: 469-477.

30. Ganschow R, Grabhorn E, Schulz A, et al. Long term results of basiliximab induction immunosuppression in pediatric liver transplant recipients. Pediatr Transplant. 2005;9:741-745.

31. Asensio M, Margarit C, Chavez R, et al. Induction with basiliximab reduces acute rejection in pediatric liver transplant patients treated with tacrolimus and steroids. Transplant Proc. 2002;34:1970-1971.
32. Strassburg A, Pfister ED, Arning A, et al. Basiliximab reduces acute liver allograft rejection in pediatric patients. Transplant Proc. 2002;34:2374-2375.

33. Gibelli N, Pinho-Apezzato M, Miyatani H, et al. Basiliximab-chimeric anti-IL2-R monoclonal antibody in pediatric liver transplantation: comparative study. Transplant Proc. 2004;36:956-957.

34. Ramirez CB, Marino IR. The role of basiliximab induction therapy in organ transplantation. Expert Opin Biol Ther. 2007;7:137-148.

35. Baudouin V, Crusiaux A, Haddad E, et al. Anaphylactic shock caused by Immunoglobulin E sensitization after retreatment with the chimeric antiinterleukin-2 receptor monoclonal antibody basiliximab. Transplantation . 2003;76:459-463.

36. Barros VR, Rocha V, Garcia VD, et al. Anaphylactic shock after retreatment with basiliximab. Transplant Proc. 2003;35:579.

37. Gane E, Naoumov NV, Qian KP, et al. A longitudinal analysis of hepatitis C virus replication following liver transplantation. Gastroenterology. 1996; 110:167-177.

38. Fukumoto T, Berg T, Ku Y, et al. Viral dynamics of hepatitis $\mathrm{C}$ early after orthotopic liver transplantation: evidence for rapid turnover of serum virions. Hepatology. 1996;24:1351-1354.

39. Teixeira R, Papatheodoridis GV, Burrough AK. Management of recurrent hepatitis $\mathrm{C}$ after liver transplantation. J Viral Hepatitis. 2001;8:159-168.

40. Pageaux GP, Calmus Y, Boillot O, et al. Steroid withdrawal at day 14 after liver transplantation: a double blind, placebo controlled study. Liver Transpl. 2004;10:1454-1460.

41. Liu CL, Fan ST, Lo CM, et al. Interleukin-2 receptor antibody (basiliximab) for immunosuppressive induction therapy after liver transplantation: a protocol with early elimination of steroids and reduction of tacrolimus dosage. Liver Transpl. 2004;10:728-733.

42. Llado L, Xiol X, Figueras J, et al. Immunosuppression without steroids in liver transplantation is safe and reduces infection and metabolic complications: results from a prospective multicenter randomized study. J Hepatol. 2006;44:710-716.

43. Ramirez CB, Doria C, Frank A, et al. Complete steroid avoidance in adult liver transplantation with 1-year follow up: single center experience. Liver Transpl. 2009;15:S244.

44. Filipponi F, Callea F, Salizzoni M, et al. Double-blind comparison of hepatitis $\mathrm{C}$ histological recurrence rate in $\mathrm{HCV}+$ liver transplant recipients given basiliximab + steroids or basiliximab + placebo, in addition to cyclosporine and azathioprine. Transplantation. 2004;78:1488-1495.

45. Pelletier SJ, Vanderwall K, Debroy MA, et al. Preliminary analysis of early outcomes of a prospective, randomized, trial of complete steroid avoidance in liver transplantation. Transplant Proc. 2005;37:1214-1216.

46. Segev DL, Sozio SM, Shin EJ, et al. Steroid avoidance in liver transplantation: meta-analysis and meta-regression of randomized trials. Liver Transpl. 2008;14:512-525.

47. Ojo AO, Held PJ, Port FK, et al. Chronic renal failure after transplantation of a non-renal organ. N Engl J Med. 2003;349:931-940.

48. Davis CL, Davis CL, Gonwa TA, et al. Pathophysiology of renal disease associated with liver disorders: implications for liver transplantation. Liver Transpl. 2002;8:91-109.

49. Gonwa TA, Melton LB, Hays SR, et al. End stage renal disease (ESRD) after orthotopic liver transplantation (OLTX) using calcineurin-based immunotherapy: risk of development and treatment. Transplantation. 2001;72:1934-1939.

50. Velidedeoglu E, Bloom RD, Crawford MD, et al. Early kidney dysfunction post liver transplantation predicts late chronic kidney disease. Transplantation. 2004;77:553-556.

51. Sellers MT, McGuire BM, Haustein SV, et al. Two-dose daclizumab induction therapy in 209 liver transplants: a single-center analysis. Transplantation. 2004;78:1212-1217.

52. Yoshida EM, Marotta PJ, Greig PD, et al. Evaluation of renal function in liver transplant recipients receiving daclizumab (Zenapax), mycophenolate mofetil, and a delayed, low-dose tacrolimus regimen vs a standard-dose tacrolimus, mycophenolate mofetil regimen: a multicenter randomized clinical trial. Liver Transpl. 2005;11:1064-1072. 
53. Tchervenkov JI, Tzimas GN, Cantarovich M, et al. The impact of thymoglobulin on renal function and calcineurin inhibitor initiation in recipients of orthotopic liver transplant: a retrospective analysis of 298 consecutive patients. Transplant Proc. 2004;36:1747-1752.

54. Lin CC, Chuang FR, Lee CH, et al. The renal-sparing efficacy of Basiliximab in adult living donor liver transplantation. Liver Transplant. 2005;11:1258-1264.

55. Arora N, McKiernan PJ, Beath SV, et al. Concomitant basiliximab with low-dose calcineurin inhibitors in children post-liver transplantation. Pediatr Transplant. 2002;6:214-218.

56. Varo E, Lopez A, Castroagudin J, et al. Alternative immunosuppression for acute renal failure in liver transplantation: role of ultra-low dose of tacrolimus and Basiliximab. Transplant Proc. 2002;34:1533-1534.

57. Younes BS, McDiarmid SV, Martin MG, et al. The effect of immunosuppression on posttransplant lymphoproliferative disease in pediatric liver transplant patients. Transplantation. 2000;70:94-99.

58. Klein A. Tacrolimus rescue in liver transplantation patients with refractory rejection or intolerant malabsorption of cyclosporine. The US Multicenter FK506 Liver Study Group. Liver Transplant Surg. 1999;5:502-508.
59. Aw MM, Taylor RM, Verma A, et al. Basiliximab (Simulect) for the treatment of steroid-resistant rejection in pediatric liver transplant recipients: a preliminary experience. Transplantation. 2003;75:796-799.

60. Orr DW, Portmann BC, Knisely AS, et al. Anti-interleukin-2 receptor antibodies and mycophenolate mofetil for treatment of steroid-resistant rejection in adult liver transplantation. Transplant Proc. 2005;37:4373-4379.

61. Fernandes ML, Lee YM, Sutedja D, et al. Treatment of steroid-resistant acute liver transplant rejection with basiliximab. Transplant Proc. 2005;37:2179-2180.

62. Lorber MI, Fastenau J, Wilson D, et al. A prospective economic evaluation of Basiliximab (Simulect) therapy following renal transplantation. Clin Transplant. 2000;14:479-485.

63. Keown PA, Balshaw R, Krueger H, et al. Economic analysis of Basiliximab in renal transplantation. Transplantation. 2001;71:1573-1579.

64. Walters SJ, Whitfield M, Akerhurst RL, et al. Economic implications of the use of Basiliximab in addition to triple immunosuppressive therapy in renal allograft recipients. Pharmacoeconomics. 2003;21:129-138.
Transplant Research and Risk Management

\section{Publish your work in this journal}

Transplant Research and Risk Management is an international, peerreviewed open access journal focusing on all aspects of transplantation and risk management to achieve optimal outcomes in the recipient improving survival and quality of life. The journal welcomes submitted papers covering original research, basic science, clinical studies,

\section{Dovepress}

reviews \& evaluations, guidelines, expert opinion and commentary, case reports and extended reports. The manuscript management system is completely online and includes a very quick and fair peer-review system, which is all easy to use. Visit http://www.dovepress.com/ testimonials.php to read real quotes from published authors. 